\title{
A Study of the Effect of Strain Rate and Temperature on the Characteristics of Quasi-Unidirectional Natural Fibre Reinforced Composites
}

\author{
O S David-West ${ }^{\mathrm{a}}$, W M Banks ${ }^{\mathrm{b}^{*}}$ and R A Pethrick ${ }^{\mathrm{c}}$ \\ ${ }^{\text {a }}$ School of Mechanical and Aerospace, Queen's University, Belfast, BT9 5AH \\ ${ }^{\mathrm{b}}$ Department of Mechanical Engineering, University of Strathclyde, Glasgow G1 1XJ. \\ ${ }^{c}$ Department of Pure and Applied Chemistry, University of Strathclyde, Glasgow G1 1XL \\ * Corresponding author: \\ Phone: 01415482321 \\ Fax: $\quad 01415525105$ \\ E-mail: bill.banks@strath.ac.uk
}

\begin{abstract}
The responses of quasi-unidirectional vegetable fibres (sisal and flax) - styrene polyester matrix composites under $6 \mathrm{~J}$ nominal strike energy at different sample temperatures and at higher impact energies of $9 \mathrm{~J}$ and $12 \mathrm{~J}$ for samples at room temperature have been studied and indentation properties realized from static loading at different crosshead displacement speeds. The findings are explained in terms of the impact characteristics. At temperatures above ambient there were changes in the impact characteristics. The drop impact tests were carried out on samples $(70 \mathrm{~mm} \mathrm{x}$ $70 \mathrm{~mm} \times 5 \mathrm{~mm}$ ) at an ambient temperature of $18^{\circ} \mathrm{C}$ and elevated temperatures of $40^{\circ} \mathrm{C}$, $60^{\circ} \mathrm{C}, 80^{\circ} \mathrm{C}$ and $100^{\circ} \mathrm{C}$ using an instrumented drop tester with a $12.1 \mathrm{~mm}$ diameter hemispheric tup and the load history and energy profile were obtained. The actual damage response depends on many intrinsic and extrinsic factors, including the thickness of the laminate, the exact stacking sequence, the shape and kinetic energy of the impactor and the degree to which the laminate is supported against bending. The examination of the impact and post impact characteristics at elevated temperatures revealed a plastic mode of failure and the performance was assessed in terms of contact time, post impact displacement and total energy. Composites are generally brittle in nature and respond elastically with little or no plastic deformation, but this is not the case for natural fibre - styrene polyester matrix composites especially at high temperatures as there exists some degree of plasticity seen in the after impact state of the samples. Low energy impact $(6 \mathrm{~J})$ results in cracking of the matrix leading to reduction in the strength of the composite. But higher energy impact strikes produce cracking of the matrix and splintering of the fibres. From the load - indentation curves average power coefficients of 3.6 and 15.4 were obtained for sisal and flax composites respectively as against 1.5 for the special Hertz contact of two elastic bodies.
\end{abstract}

Keywords: composites, natural fibres, loading rate, contact indentation, Mayer's law, dynamic loading, temperature effect, contact time, total energy, post impact displacement

\section{Introduction}


Composites made with synthetic fibres provide good thermal and mechanical properties compared to composites reinforced with natural fibres; but there is a problem to get suitable disposal methods. Authorities and users of composites are therefore concerned about suitable techniques for the disposal or recycling of composites reinforced with synthetic fibres (such as glass, carbon, kevlar etc), as present government policies are pointing to applications using environmentally friendly materials. This is one reason for the increased use of natural fibre composites in the interiors of cars by the manufacturers; also the ability of plant fibres to absorb humidity leads to increased comfort that cannot be reached with synthetic materials.

The use of natural fibres as reinforcements in composites represents a suitable alternative to some synthetic fibres. These natural fibres are usually treated to enhance the composite properties. Though natural fibres' mechanical properties are much lower than those of synthetic fibres [eg glass] their specific properties, especially specific stiffness of some of the fibres are higher than those of glass fibres [1]. The use of specific properties implies a reduction in the weight saving of the design. Natural fibres are biodegradable, light, cheap and available. In some applications a binder is used to help bond the fibres together.

In our every day life impacts on objects are inevitable and composites are subjected to different forms of impact strike from time to time. In general low energy impact occurs during the assembly or maintenance of the structures (ie at ambient temperature), but the component might experience temperatures of various values in service. When subjected to impact loading, energy is absorbed in the formation of fresh surfaces; through certain damage modes such as matrix cracks, fibre fracture, etc. Even when the damage due to impact is invisible, matrix cracking might have occurred and the load carrying capacity of the composite be reduced as the matrix binds the fibres together and distributes loads to the fibres. Visible damage occurs at threshold impact energy, depending on the stiffness of the composite [2, 3]. Although, laminated composite materials are used extensively, their behaviour under impact is still a discussion topic within the composite community. Some reviews on the studies of impact on composite materials have been presented by Abrate [4, 5].

Woven carbon/epoxy laminates were subjected to low velocity impact loading at energy levels of 15, 30 and $45 \mathrm{~J}$ by Hosur M V et al [6]. Samples were subjected to different conditions that included base line room temperature, cold dry, cold moist, heat dry, hot wet and thermal cycling. Impact parameters like peak load, absorbed energy, time to peak and energy at peak load were evaluated and compared. It was noted that samples subjected to conditioning exhibited better impact behaviour and lower damage sizes as compared to that of room temperature samples. Gomez-del Rio, $\mathrm{T}$ et al [7], reported that cooling the laminate before impact has an effect on damage similar to that of increasing the impact energy, after subjecting carbon fibre reinforced epoxy matrix laminates to temperatures ranging from $20{ }^{0} \mathrm{C}$ down to -150 ${ }^{0} \mathrm{C}$ and performed at low velocity impact. Nano particles are useful in improving matrix properties of a composite; in a study Hosur et al [8] subjected woven carbon/epoxy - nanoclay composites to low energy drop impact tests. The response of the composites was presented as load - energy vs time relations and the conclusion as expected: the inclusion of nanoclay reduced the effect of the impact strike in respect of damage.

Wambua et al [9] have reported the ballistic characteristics of composites reinforced with flax, hemp and jute, with and without mild steel facing sheet. Better absorption 
of the energy was displayed by the flax composites, compared to the ones manufactured with hemp or jute. Improvements in the ballistic properties were obtained when mild steel sheets are used as facing and backing, making the structure a sandwich.

A number of experimental and analytical studies have been reported on the dynamic characteristics of composites reinforced with synthetic fibres, but only very few have been investigated and published on the impact behaviour of natural fibre reinforced composites. Impact performance and damage tolerance studies are important issues for discussion in the research community; hence it is necessary to have some understanding of the mechanisms governing behaviour and performance of green composites under impact loading. However, the impact performance or the behaviour at high strain rates of natural fibre composites is probably a significant and not much discussed phenomena. In this paper we have reported an investigation on the characteristics of non hybrid composites reinforced with sisal and flax at ambient and elevated temperatures.

\section{Materials}

\subsection{Fibres}

The fibres used in this study were sisal and flax. They were used for this study as obtained from the manufacturers (Wigglesworth Limited) and each kind was obtained from a specific source. As the fibres were obtained from one source it may be assumed that the fibres were grown under similar environmental conditions. In this way, growth environmental effect may be thought to be reduced.

\subsection{Cured resin}

The properties of the resin (Crystic 703PA) cured at ambient temperature for 24 hours, as reported by the manufacturers 'Scott Bader' is as shown in Table 1.

Table 1: Properties of cured resin.

\begin{tabular}{|l|l|}
\hline Tensile Strength (MPa) & 49 \\
\hline Tensile Modulus (MPa) & 2758 \\
\hline Elongation at Break (\%) & 2.1 \\
\hline
\end{tabular}

Crystic 703A is a pre-accelerated polyester resin, produced by Scott Bader and the catalyst applied was Methyl Ethyl Ketone Peroxide. The resin has a viscosity of 1.6 poise at $25^{\circ} \mathrm{C}$. These materials were used as obtained from the manufacturer for this study, without any further reaction with some chemicals.

\section{Samples' manufacture}

The properties of vegetable fibres are highly variable. They are usually affected by the environmental and growth conditions; it is difficult therefore to get consistent results. The vegetable fibres were processed into unidirectional green composites by hand laying in a mould and the fibre volume fraction was approximately $40 \%$ determined by mass measurement with the use of fibre and resin densities. The resin mixed properly with the catalyst by manual stirring was atmospherically cast into the mould. The mould was then covered with a heavy plate and allowed to cure for 24 hours. The catalyst proportion was between $1-2 \%$ of the resin as recommended by the manufacturer. Fig. 1 shows photographs of the manufactured samples. 


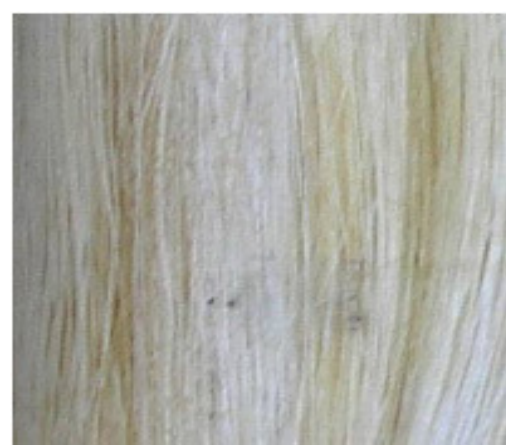

Sisal

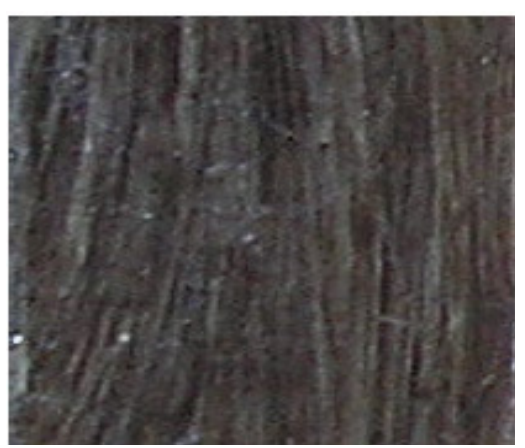

Flax

Fig. 1: Photographs of manufactured samples

\section{Experimental Programme}

\subsection{Impact Test}

Coupon size test specimens measuring $70 \mathrm{~mm} \times 70 \mathrm{~mm} \times 5 \mathrm{~mm}$ were subjected to low energy drop tests using an instrumented falling weight drop tester with an available $12.1 \mathrm{~mm}$ diameter hemispheric tup. The nominal impact energy and number of tests are as shown in Table 2. The samples used for this investigation were tested at ambient and elevated temperatures to investigate the effect of temperature.

Table 2: Experimental Programme (dynamic loading).

\begin{tabular}{|c|c|c|c|c|c|c|c|c|c|}
\hline \multicolumn{4}{|c|}{ Ambient temperature $\left(18^{0} \mathrm{C}\right)$} & \multicolumn{6}{|c|}{ Elevated temperatures } \\
\hline \multicolumn{2}{|c|}{ Sisal + resin } & \multicolumn{2}{|c|}{ Flax + resin } & & & \multicolumn{2}{|c|}{ Sisal + resin } & \multicolumn{2}{|c|}{ Flax + resin } \\
\hline $\begin{array}{c}\text { Impact } \\
\text { energy } \\
\text { (J) }\end{array}$ & $\begin{array}{c}\text { No of } \\
\text { tests }\end{array}$ & $\begin{array}{c}\text { Impact } \\
\text { energy } \\
(\mathrm{J})\end{array}$ & $\begin{array}{c}\text { No of } \\
\text { tests }\end{array}$ & & & $\begin{array}{c}\text { Impact } \\
\text { energy } \\
(\mathrm{J})\end{array}$ & $\begin{array}{l}\text { No } \\
\text { of } \\
\text { tests }\end{array}$ & $\begin{array}{c}\text { Impact } \\
\text { energy } \\
(\mathrm{J})\end{array}$ & $\begin{array}{l}\text { No } \\
\text { of } \\
\text { tests }\end{array}$ \\
\hline 6 & 2 & 6 & 2 & & 40 & 6 & 2 & 6 & 2 \\
\hline 9 & 2 & 9 & 2 & & 60 & 6 & 2 & 6 & 2 \\
\hline 12 & ? & 12 & & & 80 & 6 & 2 & 6 & 2 \\
\hline 12 & 2 & 12 & 2 & & 100 & 6 & 2 & 6 & 2 \\
\hline
\end{tabular}

\subsection{Static loading}

Indentation experiments were performed on coupon size samples of $70 \mathrm{~mm} \times 70 \mathrm{~mm} \mathrm{x}$ $5 \mathrm{~mm}$, using the procedure similar to the one used by Md Akil Hazizan and W J Cantwell [10] in their study. The experiments were performed under ambient conditions, with a 'ZWICK REL Model 2061 Universal Testing Machine' at test speeds shown in Table 3.

Table 3: Experimental programme (static loading).

\begin{tabular}{|c|c|c|c|}
\hline \multicolumn{2}{|c|}{ Sisal+ resin } & \multicolumn{2}{c|}{ Flax + resin } \\
\hline $\begin{array}{c}\text { Speed } \\
(\mathrm{mm} / \mathrm{min})\end{array}$ & $\begin{array}{c}\text { No of } \\
\text { tests }\end{array}$ & $\begin{array}{c}\text { Speed } \\
(\mathrm{mm} / \mathrm{min})\end{array}$ & $\begin{array}{c}\text { No of } \\
\text { tests }\end{array}$ \\
\hline 0.5 & 2 & 0.5 & 2 \\
\hline 5 & 2 & 5 & 2 \\
\hline 8 & 2 & 8 & 2 \\
\hline
\end{tabular}

\section{Drop impact testing}


The impact tests in this study were performed on the instrumented drop tester model MOM40 manufactured by ROSAND. The features of the impact testing machine which was used for the drop load tests are shown in reference [3]. The change in the impact energy for this system was achieved by changes in the drop height as the mass is fixed at $30 \mathrm{~kg}$. The sample is held fixed by a pneumatic press at a pressure of $8 \mathrm{bar}$ during testing to prevent sample vibration. In this study an available $12.1 \mathrm{~mm}$ diameter tup having hemispherical end was used. The impact energy is absorbed in the elastic deformation, plastic deformation and by the different forms of damage modes.

Transient response of the composite was measured and stored. The impact parameters obtained included load, energy, velocity and displacement as a function of time. The system measures the load - time response through the load cells. The other parameters were calculated by the application of the laws of motion. The energy that goes into the composite is calculated based on conservation of energy principles and is calculated based on the potential energy of the impactor, initial kinetic energy of the impactor at the time of impact and instantaneous kinetic energy.

As the composites manufactured were hand laid, they are quasi-unidirectional and the matrix binds the fibres together. The indentation is localised but the strain effect is expected to vary along the entire sample. The shape of trace may be affected by the fibre - matrix bonding, varying properties of vegetable fibres, fibre alignment and location of the indenter.

\section{Static loading test}

The indentation properties of the composites were investigated on a ZWICK REL Model 2061 Universal Testing Machine, at crosshead displacement rates of 0.5, 5 and 8 (all in $\mathrm{mm} /$ minute) and a schematic of the test arrangement is shown in Fig. 2.

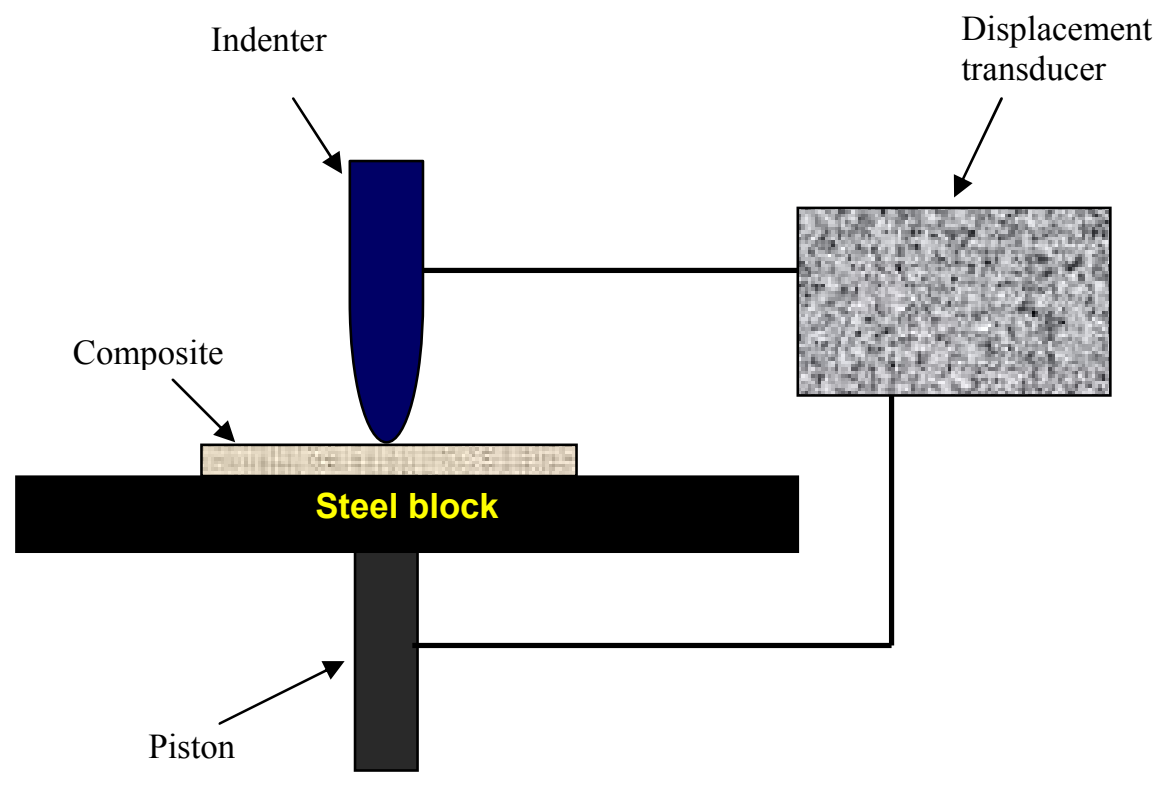

Fig. 2: The schematic drawing of the test arrangement 
The applied load, P; and the resulting indentation, $\alpha$; were assumed to obey Meyer's indentation law which takes the form

$$
P=C \alpha^{n}
$$

where $\mathrm{C}$ and $\mathrm{n}$ are constants which were determined by fitting the experimental data to this relationship. The energy absorbed due to contact effects can be estimated by integrating the above equation from zero to the maximum indentation.

$$
E=\int_{0}^{\alpha_{\max }} P d \alpha
$$

The Meyer law is simply an empirical expression to describe the relationship between indentation load and the resultant indentation size. It gives suitable results only in a narrow range of indentation loads.

\section{Results of impact test}

Drop impact tests were carried out on the samples under two conditions; ambient temperature of $18^{\circ} \mathrm{C}$ and elevated temperatures of $40^{\circ} \mathrm{C}, 60^{\circ} \mathrm{C}, 80^{\circ} \mathrm{C}$ and $100^{\circ} \mathrm{C}$. The nominal strike energies (Fig. 3) were 6J, 9J and 12J for test samples at room temperature and only $6 \mathrm{~J}$ for the heated composites. Figs 4 and 5 are plots of the tests performed at ambient temperature. In some cases, the total energy after impact is more than the set or nominal energy. The reason for this is illustrated in Fig. 3 below. It is mainly because of indentation, penetration and perforation; that has generated some additional drop distance of the striker that was initially not accounted for.

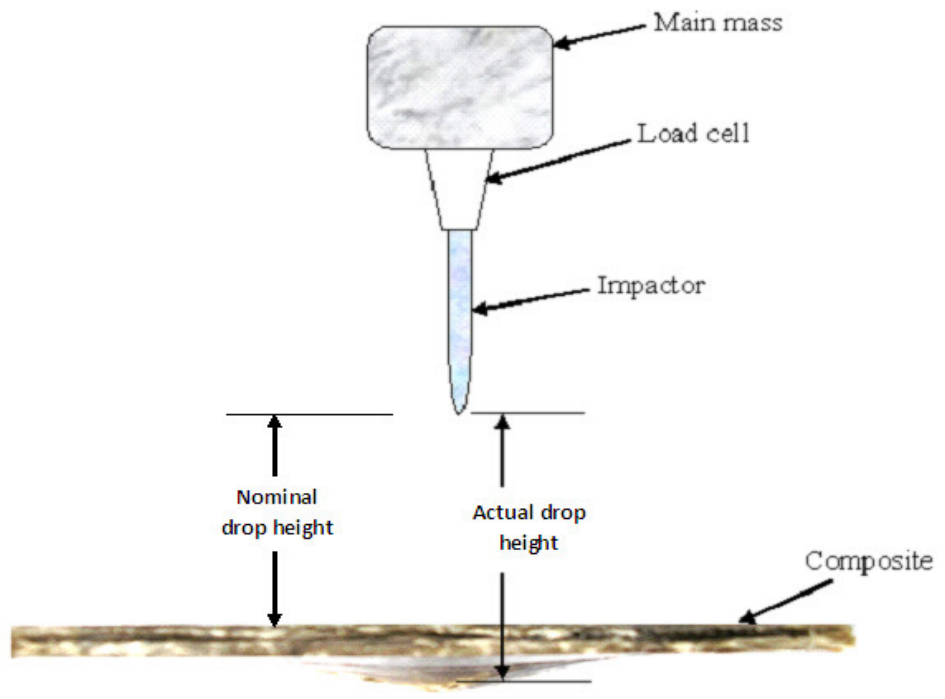

Fig. 3: An illustration of the nominal and actual drop height of the drop impact test

From the load history, the energy profile for the impact event was calculated; regardless of the impact energy the profile rises to a constant value; this being the 
quantity of energy transferred into the composite and dissipated in the generation of damages.

\begin{tabular}{|ccc|}
\hline - Force history $6 \mathrm{~J}$ impact & - Force history $9 \mathrm{~J}$ impact & - Force history $12 \mathrm{~J}$ impact \\
Energy history $6 \mathrm{~J}$ impact & Energy history $9 \mathrm{~J}$ impact & - Energy history $12 \mathrm{~J}$ impact \\
\hline
\end{tabular}

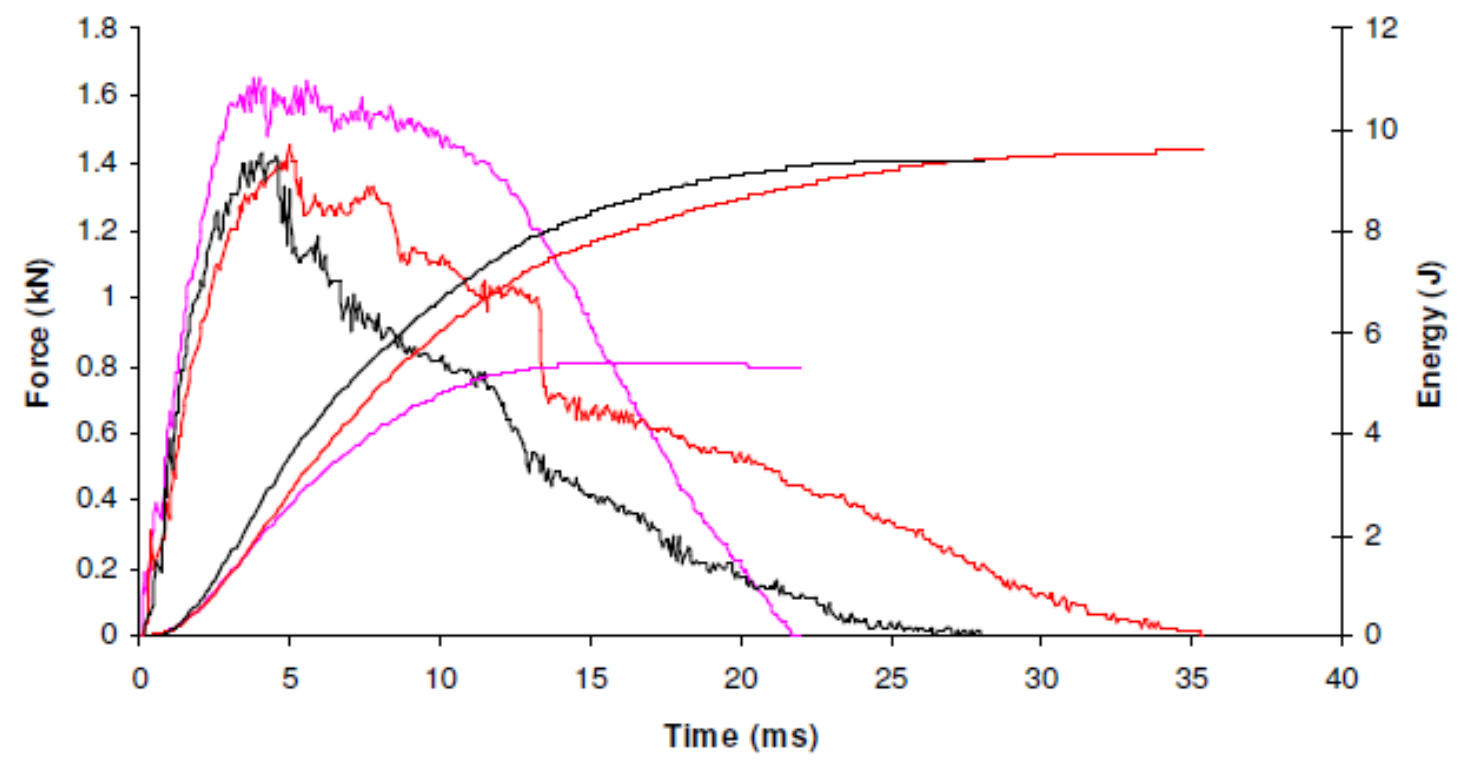

Fig. 4: Impact force - time response and calculated energy curve for sisal fibre composites
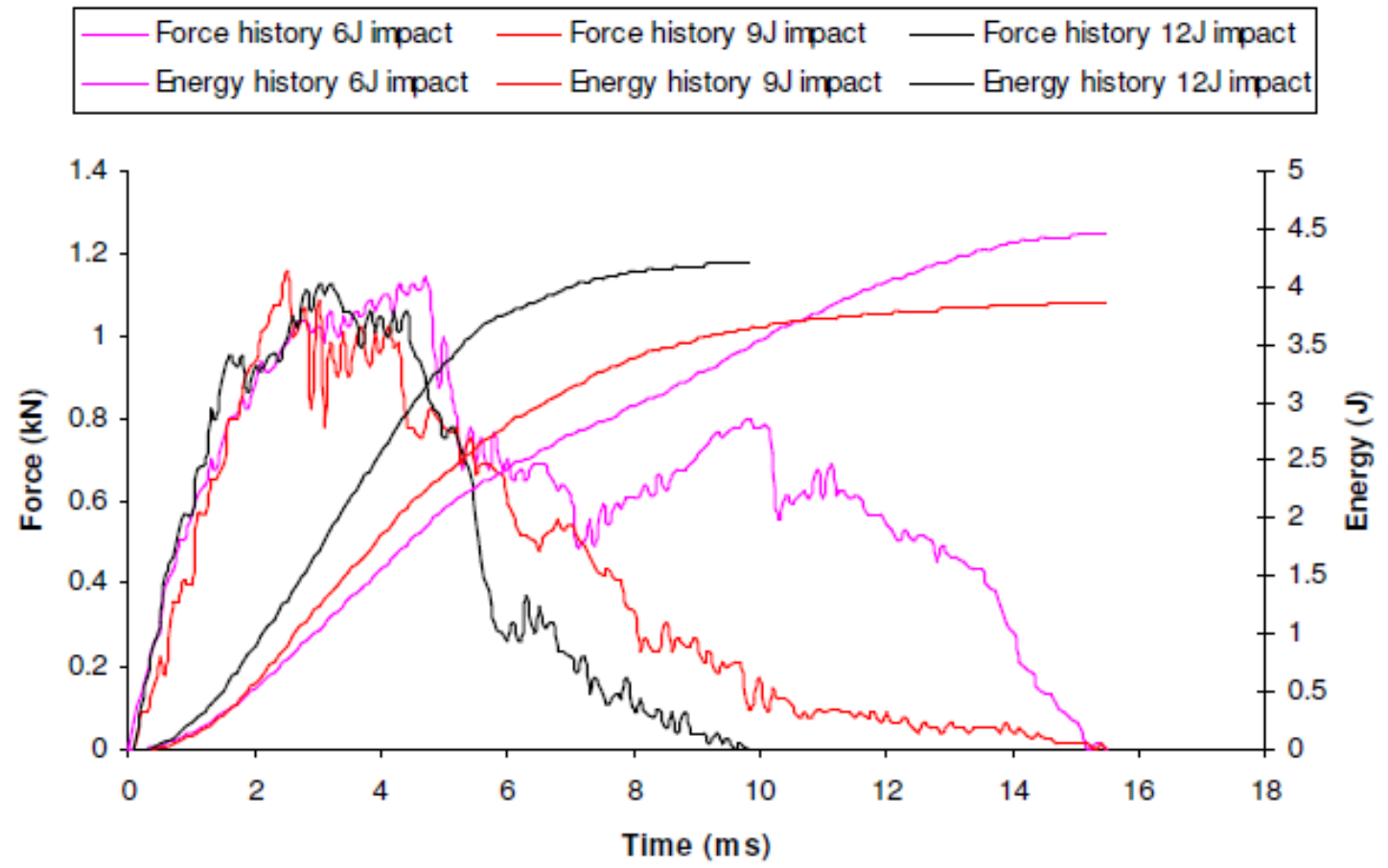

Fig. 5: Impact force - time response and calculated energy curve for flax fibre composites

Composites are generally brittle in nature and respond elastically with little or no plastic deformation, but this might not be the case for natural fibre - styrene polyester 
matrix composites, especially at high temperatures as there exist some degree of plasticity seen in the after impact state of the samples. If the damage within the specimen is very small the load - time plot will be minimal stick - slip in the plot and it may be almost symmetrical about the peak load. As the impact effect is more localized around the point of contact (Fig. 6), the strain at the point of impact is expected to be highest and to decrease towards the boundaries. Impact $(6 \mathrm{~J})$ result in cracking of the matrix leads to reduction in the strength of the composite, but delamination is not expected as it is a unidirectional composite. Also when there is no sharp drop in load the effect of the impact has not caused enough damage to reduce the strength of the laminate, the effect being concentrated within the impact contact point.

The actual damage response depends on many intrinsic and extrinsic factors, including the thickness of the laminate, the exact stacking sequence, the shape and kinetic energy of the impactor, and the degree to which the laminate is supported against bending. The strain-to-failure capability of the fibres will determine the degree of back-face damage in a given laminate, and the area of the damage depends on the toughness of the matrix and fiber/matrix bond strength as well as the failure strain and stiffness of the fibres.

The initial rise in the load history plots is almost smooth and identical, indicating an elastic response up to the point of load drop and the stick - slip drop in load implies progressive local failure of the composite, especially after the peak (Figs. 4 and 5). With the increase in impact energy for the test at ambient temperature, the laminates undergoe large deformation, and ultimately results in tensile failure at the rear side due to flexure. At $9 \mathrm{~J}$ and $12 \mathrm{~J}$ impact there was penetration through the composite sample; when this happen the entire kinetic energy of the striker is transferred to the sample and dissipated through damage modes [11].

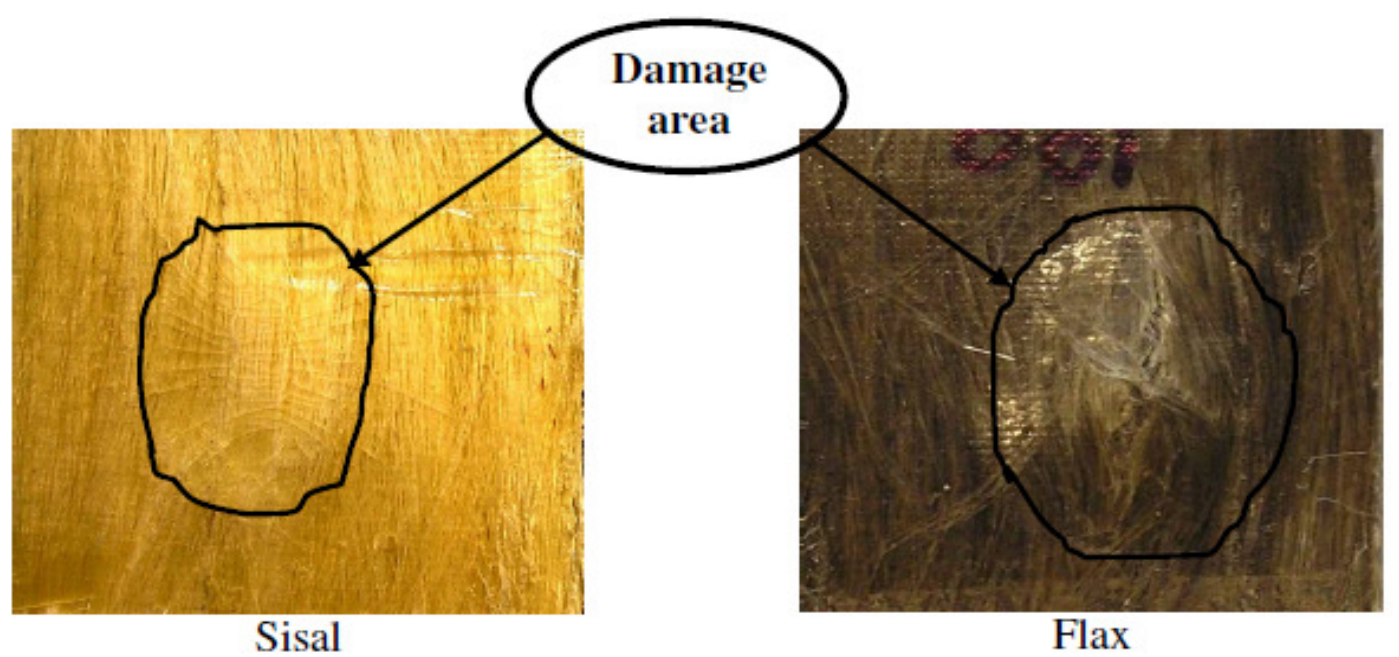

Fig. 6: Post impact images of composite plates

The micro-structural photos were taken with a Nikon Epihot metallurgical microscope at $\mathrm{x} 50$ magnification. In preparing of samples for these photos, they were (in addition to being sectioning through the impact point of the composite with an abrasive cutting disc and cooling water) mounted on Struers Durofix-2 cold mounting acrylic resin. They were then ground with 220 grit Silicon-carbide paper with cooling water at 300 rpm, followed with $800,1200,2400$ grit papers to reduce scratch pattern. Finally, they were polished with 3 micron diamond suspension with DP blue lubricant on DP-Dur 
polishing pad at $150 \mathrm{rpm}$. Fig. 7 is a micro-photograph showing the irregular crack path through a sample thickness.

The crack path is unpredictable; this is thought to be for several reasons including the following:

1. Single fibres have different ultimate strengths.

2. Fibres were hand laid.

3. The micro-fibrillar angles.

The tested samples revealed cracking of the matrix and splintering of the fibres at perforation. The fibres, which are the load bearing component, are non uniform in cross-section, coupled with variation in cross sectional shape along the fibre length. The damage area because of an impact strike is important in estimating the extent of damage; it gives a measure of how localized or global is the damage as the residual strength of the laminate depends on it.

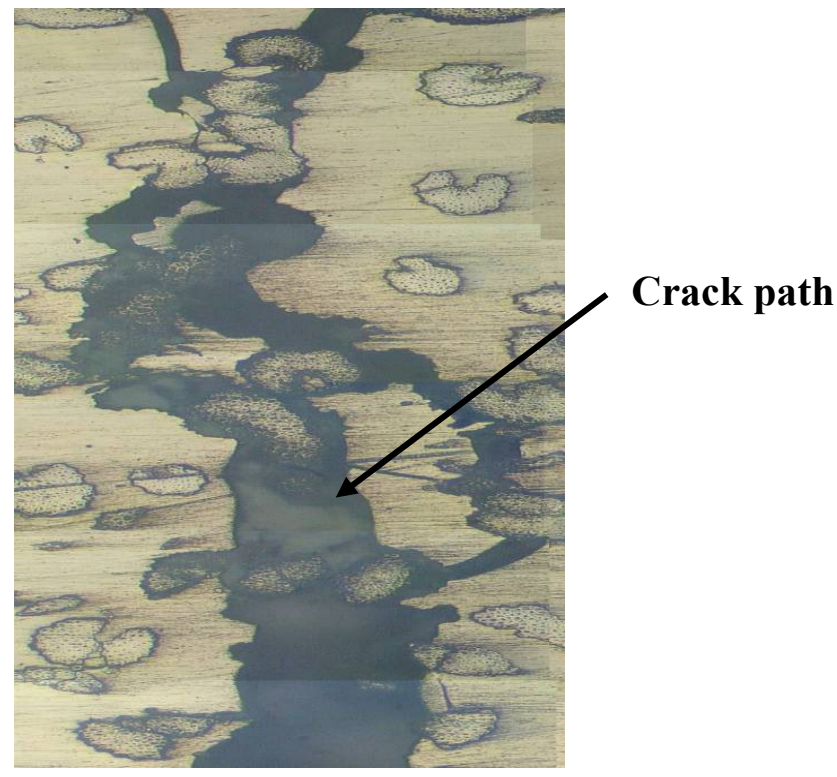

Fig. 7: A representative sample through the impact point thickness microphotograph.

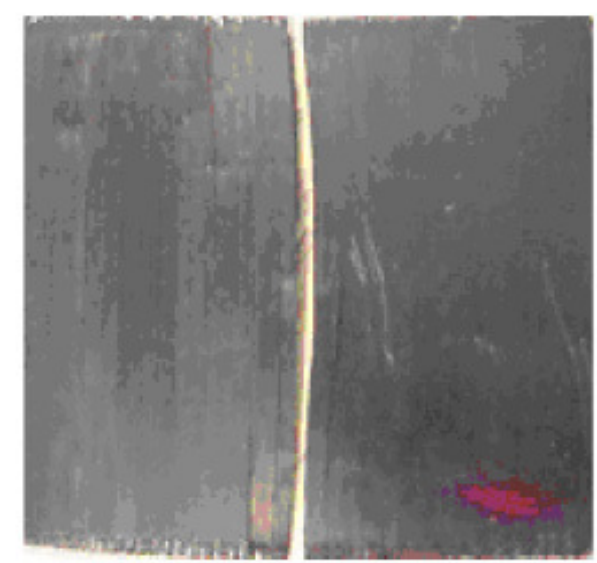

Unidirectional synthetic fibre composite

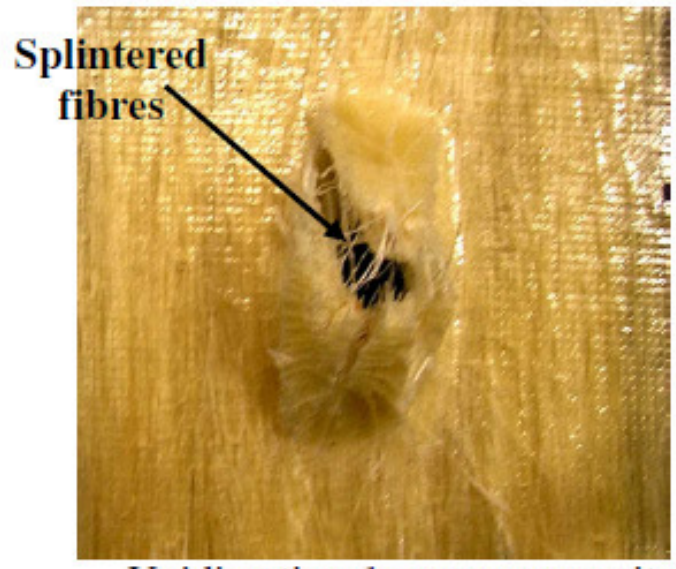

Unidirectional green composite

Fig. 8: Post impact photographs of composites

Unidirectional composite reinforced with synthetic fibre (carbon) under impact load splits into two (Fig. 8) compared to the quasi-unidirectional natural fibre reinforced 
composite which shows localized splintering of the fibres on perforation. This difference is because of the complex fracture behaviour of the composite reinforced with the natural fibres. Thus, it may be possible to conclude that the microfibrillar angles of natural fibres can retard the propagation of cracks and growth of damage in green composites. As bio-composites are emerging as a viable alternative to synthetic fibre reinforced composites; to exhibit the favourable non-brittle fracture on impact, is an important requirement particularly for passenger vehicles. They show better shatter resistant and energy dissipation characteristics compared to the synthetic fibre reinforced composite.

Perforation is an important mode of damage and the impact characteristics (such as peak force and absorbed energy) and mechanical property degradation of composite laminates reach critical values when perforation takes place. Five different phases of deformation can be observed during a perforation impact event, namely, impact contact, hydrostatic-compression, compression-shear, tension-shear and structural vibration; these phase have been highlighted by Gama et al [12]

\section{Above room temperature impact}

Figs 9 to 12 are representative graphs of force - time and energy - time of the impact events on the composite plates, manufactured with the two different types of natural fibres. Although the magnitude of the impact is the same for all tests different stress waves propagate through the different composite plates. This is thought to be because of the differences in the properties of the reinforcement fibres and the temperature of the samples.

A sudden drop (as shown by flax fibre composite - Figs. 9 and 10) in load may also be attributed to some form of damage, which may also be referred to as loss of stiffness with some strain energy stored, which later may be dissipated. The release of this energy helps to dampen the impact force and generate reactions to set the bodies apart.

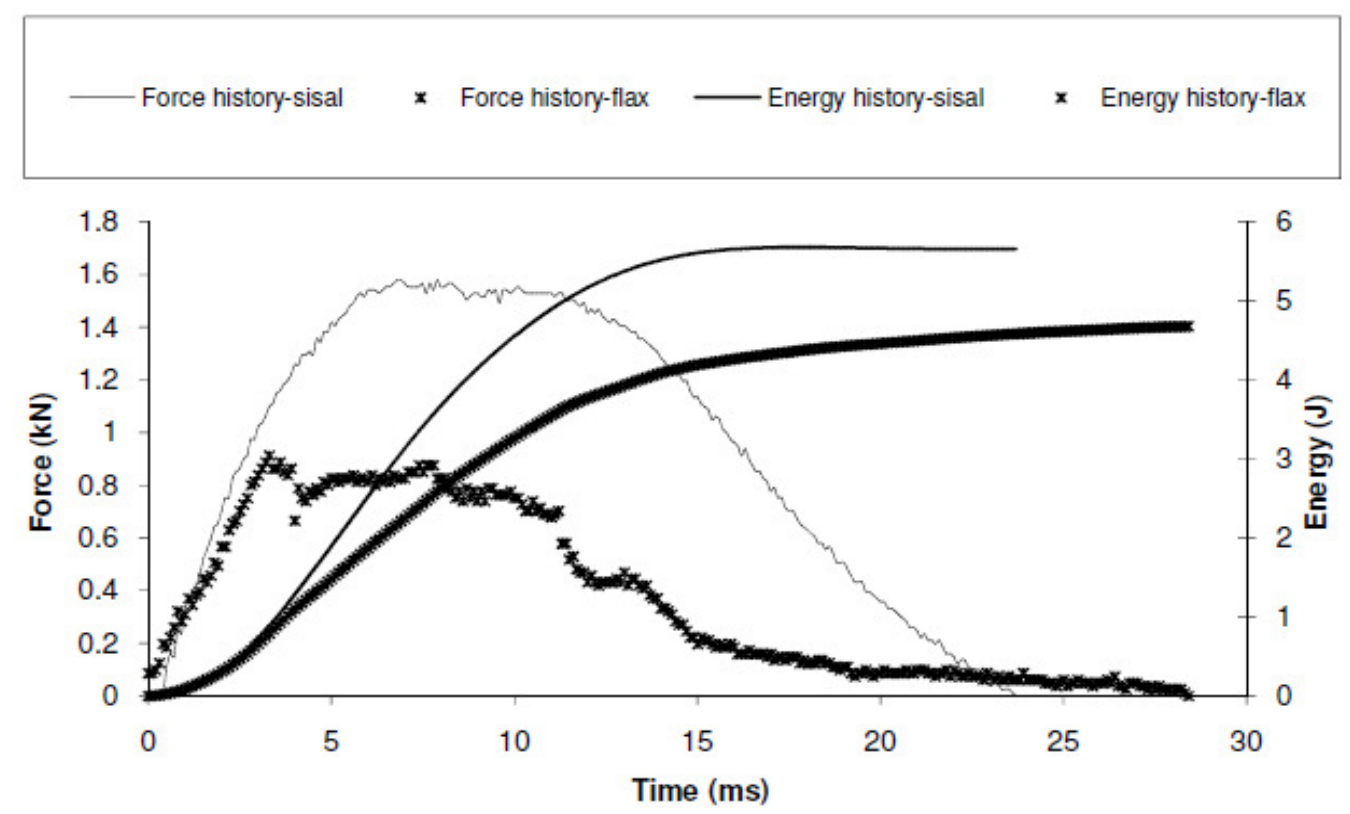

Fig. 9: Representative impact response of natural fibre composites under $6 \mathrm{~J}$ impact and sample temperature of $40^{\circ} \mathrm{C}$ 
× Force history-flax

— Force history-sisal

× Energy history-flax

——Energy history-sisal

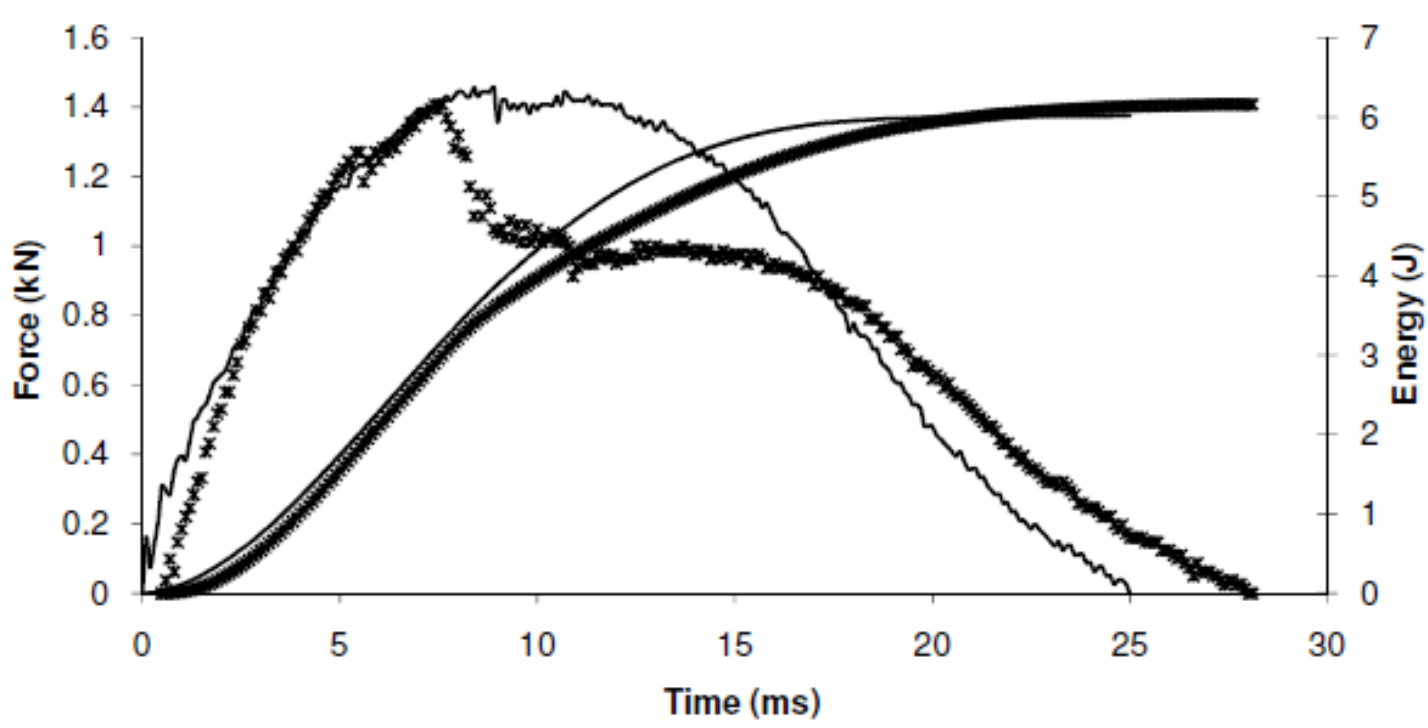

Fig. 10: Representative impact response of natural fibre composites under $6 \mathrm{~J}$ impact and sample temperature of $60^{\circ} \mathrm{C}$

x Force history-flax

__ Force history-sisal

$\times$ Energy history-flax

__Energy history-sisal

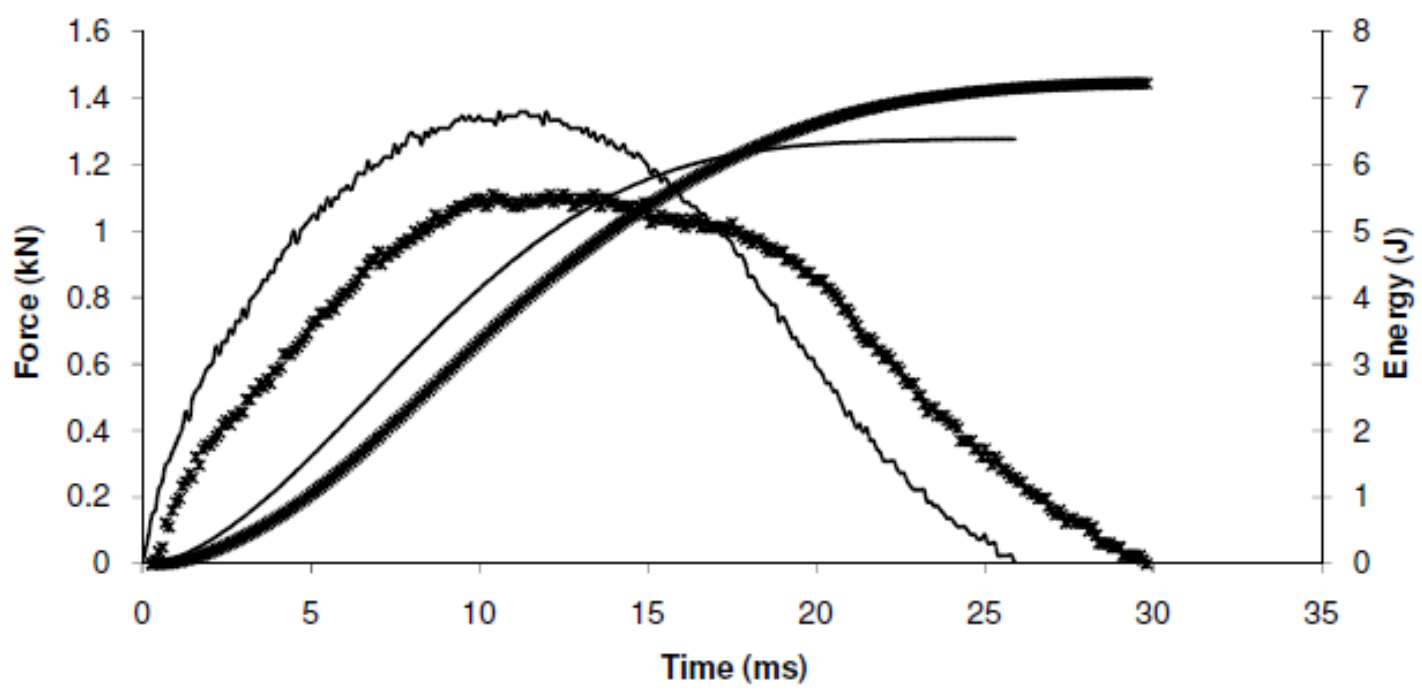

Fig. 11: Representative impact response of natural fibre composites under $6 \mathrm{~J}$ impact and sample temperature of $80^{\circ} \mathrm{C}$ 
force history-flax _ force history-sisal

x energ history-flax _ energy history-sisal

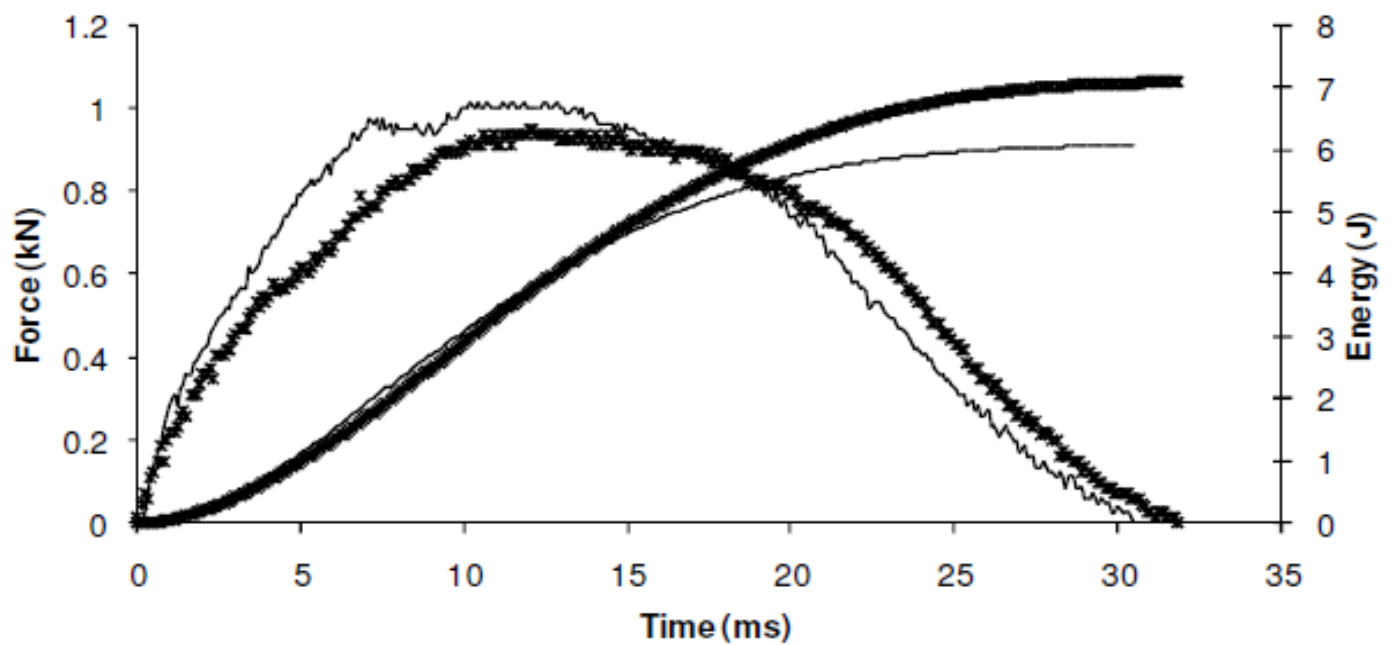

Fig. 12: Representative impact response of natural fibre composites under $6 \mathrm{~J}$ impact and sample temperature of $100^{\circ} \mathrm{C}$

The impact response such as peak load, contact time, maximum deflection and total energy obtained from the dynamic display of the composites, during the ambient and elevated temperature tests are now presented in the next section.

\section{Impact properties}

Samples at ambient temperature of $18^{0} \mathrm{C}$ were first tested and then, to investigate the effect of temperature green composite samples were tested at $40^{\circ} \mathrm{C}, 60^{\circ} \mathrm{C}, 80^{\circ} \mathrm{C}$ and $100^{\circ} \mathrm{C}$. The impact characteristics were used to compare the extent of damage in the composites. In Fig. 13 is shown the comparison of the peak loads obtained from the test for the two kinds of vegetable fibre composite. Taking consideration of the error bars at ambient temperature both composites might give similar values but at elevated temperature the composite reinforced with sisal fibre has the higher peak loads.

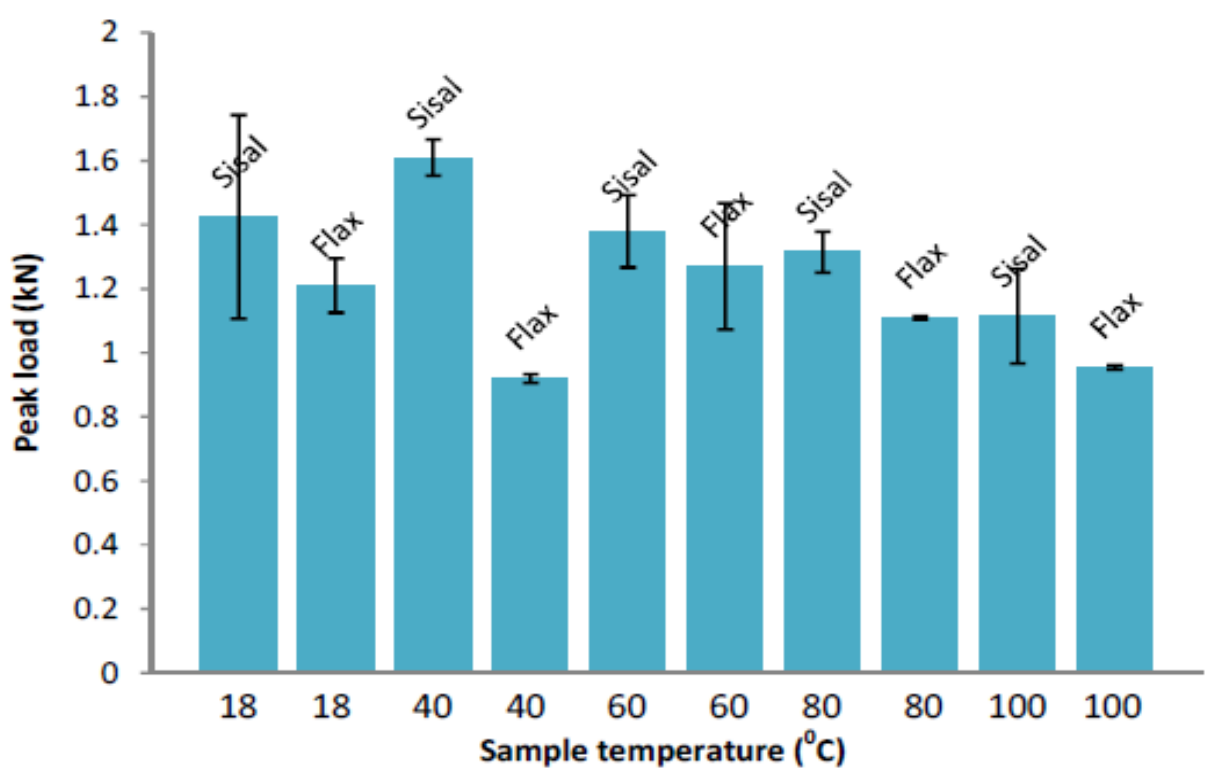

Fig. 13: Impact peak load vs sample temperature of the composites. 


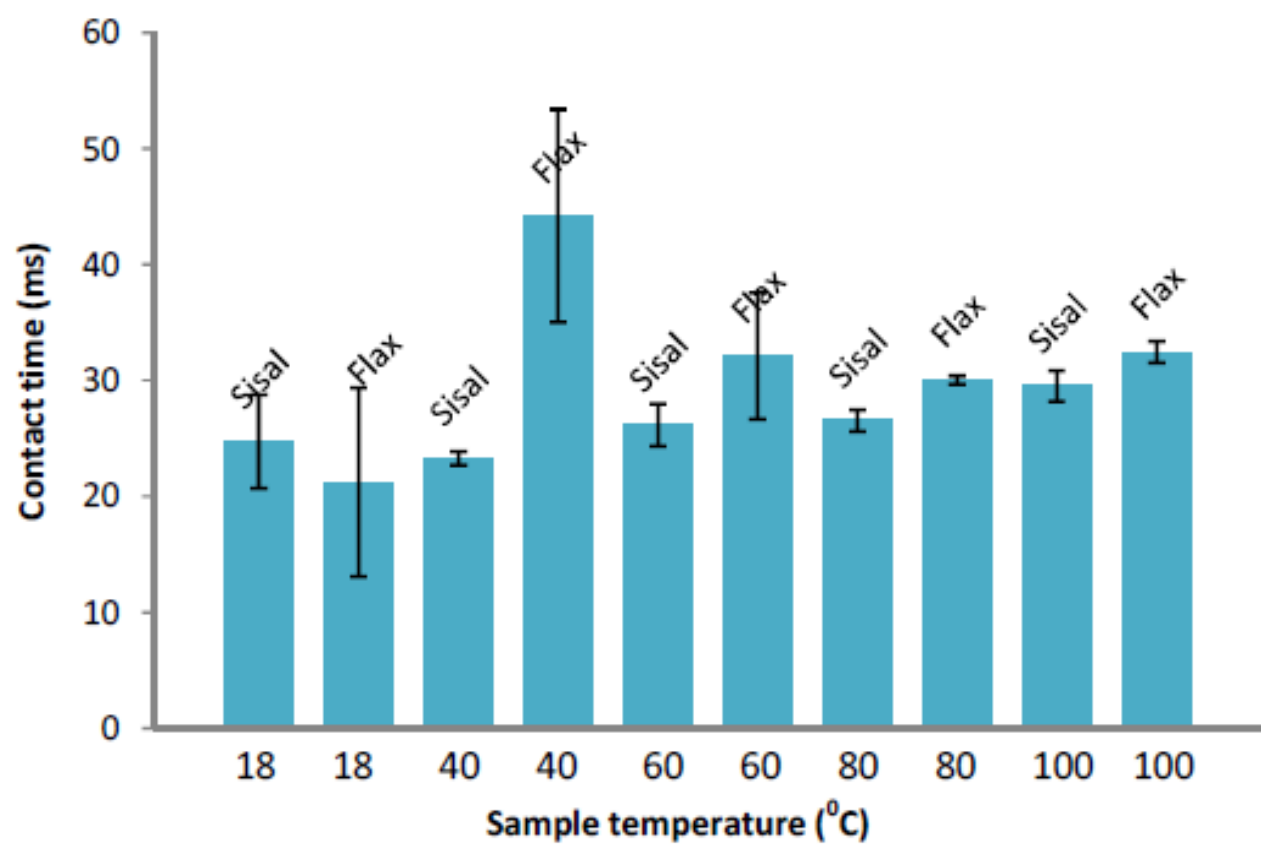

Fig. 14: Variation of contact time over a range of temperatures for the composites.

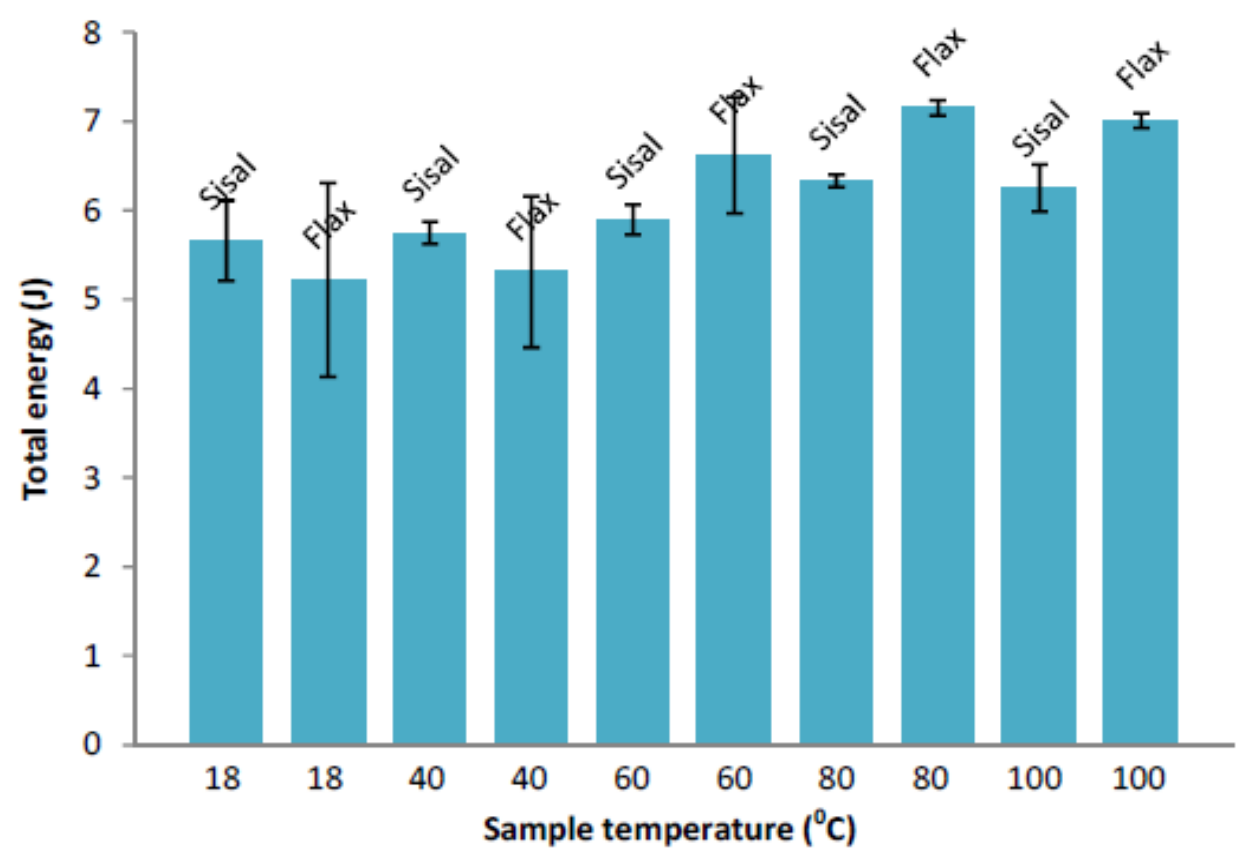

Fig. 15: Total energy vs sample temperature plot for the composites. 


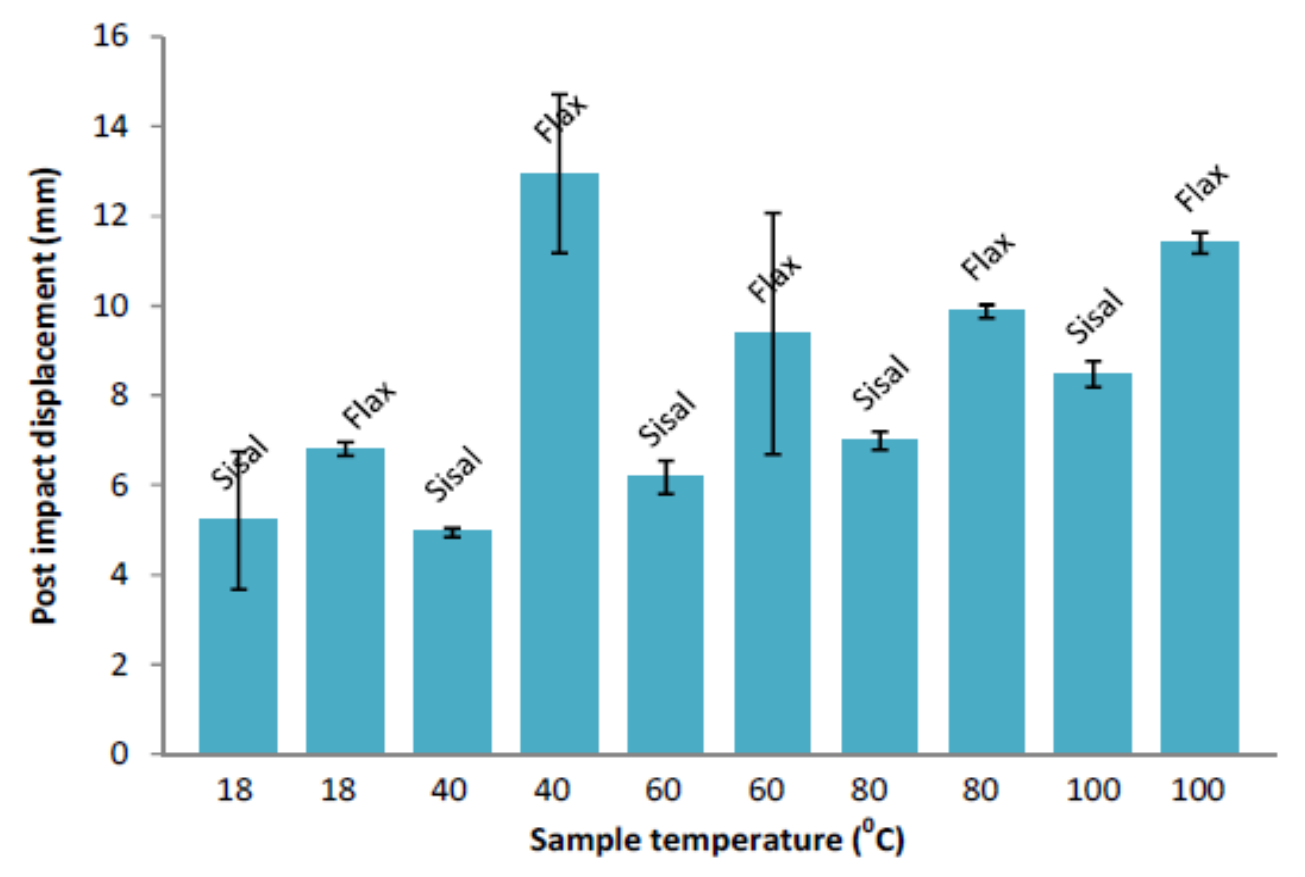

Fig. 16: The displacement of the impact point at the end of the event.

The performance of the composite reinforced with sisal at elevated temperature is better because of the reduced contact time (Fig. 14). Time is required for the creation of damage and hence the larger the time, the greater the damage. This conclusion is supported by the other impact properties: total energy and post impact displacement presented in Figs 15 and 16 respectively. That is the more the energy absorbed by the composite; the greater the damage incurred and hence increases in the displacement after the strike by the impactor.

\section{Strain rate effects}

The indentation is localised but the strain effect is expected to vary along the entire sample. The variation of indentation load and displacement with the crosshead displacement rate is shown in Figs 17 and 18. The plots are initially curved from the abscissa and then tend to be linear. The shape of trace may be affected by the fibre matrix bonding, varying properties of vegetable fibres, fibre alignment and location of the indenter. The graphs represent two sets of results. The Meyer's parameters are derived from the load - indentation data by curve fitting (average $R^{2}$ value being 0.9) by this the contact coefficients $\boldsymbol{C}$ and $\boldsymbol{n}$ were determined. 


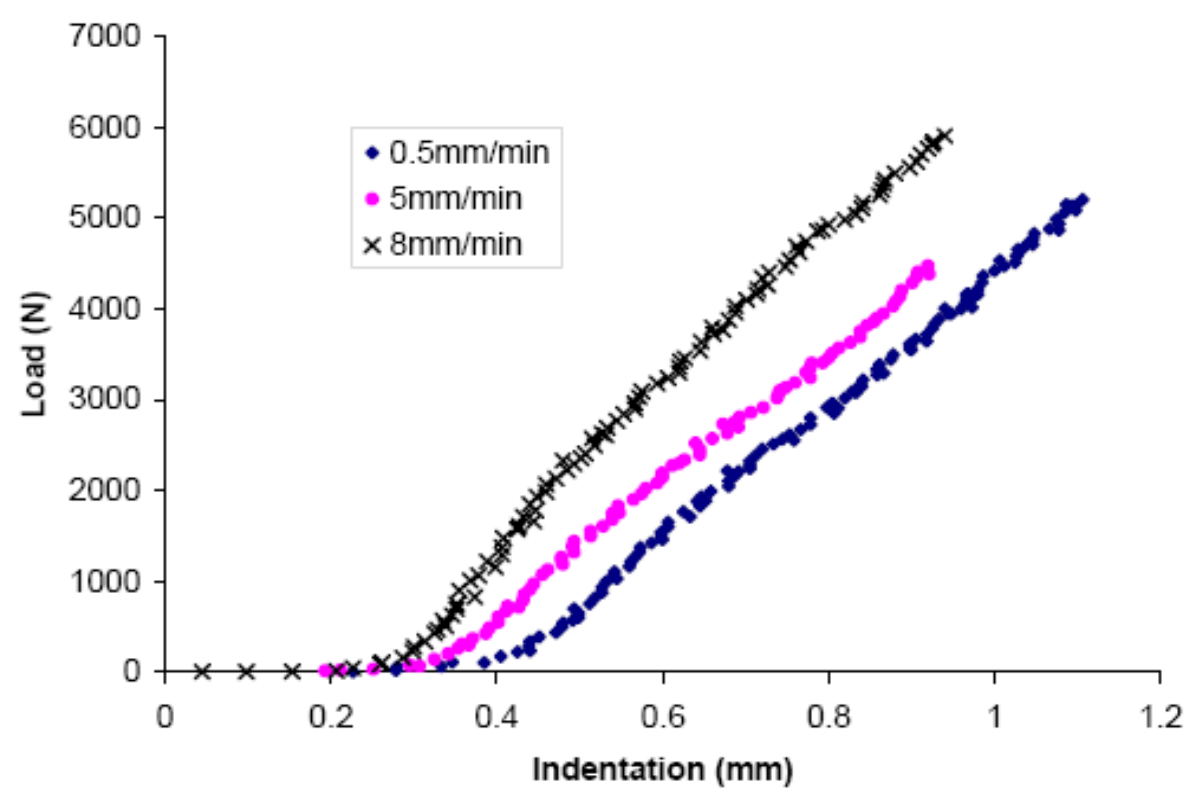

Fig. 17: Load - indentation curves following indentation test for sisal fibre biocomposite.

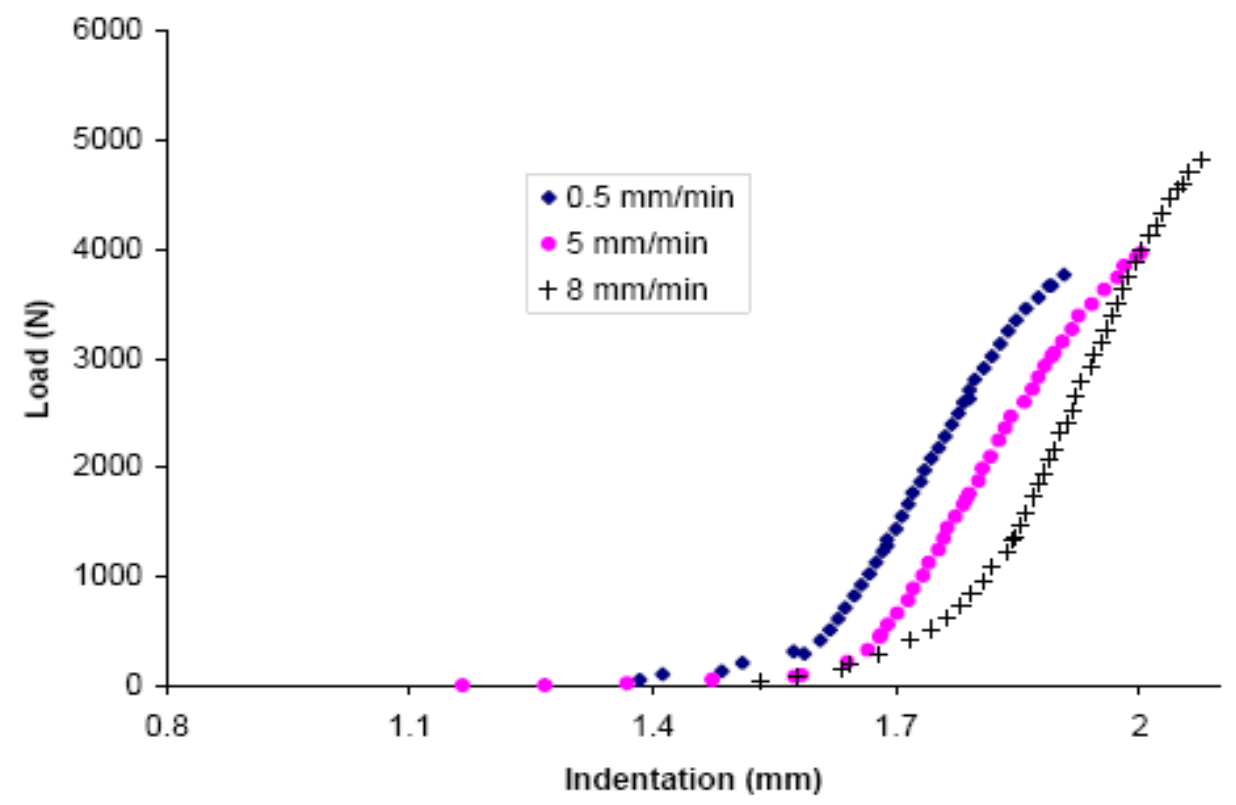

Fig. 18: Load - indentation curves following indentation test for flax fibre biocomposite. 


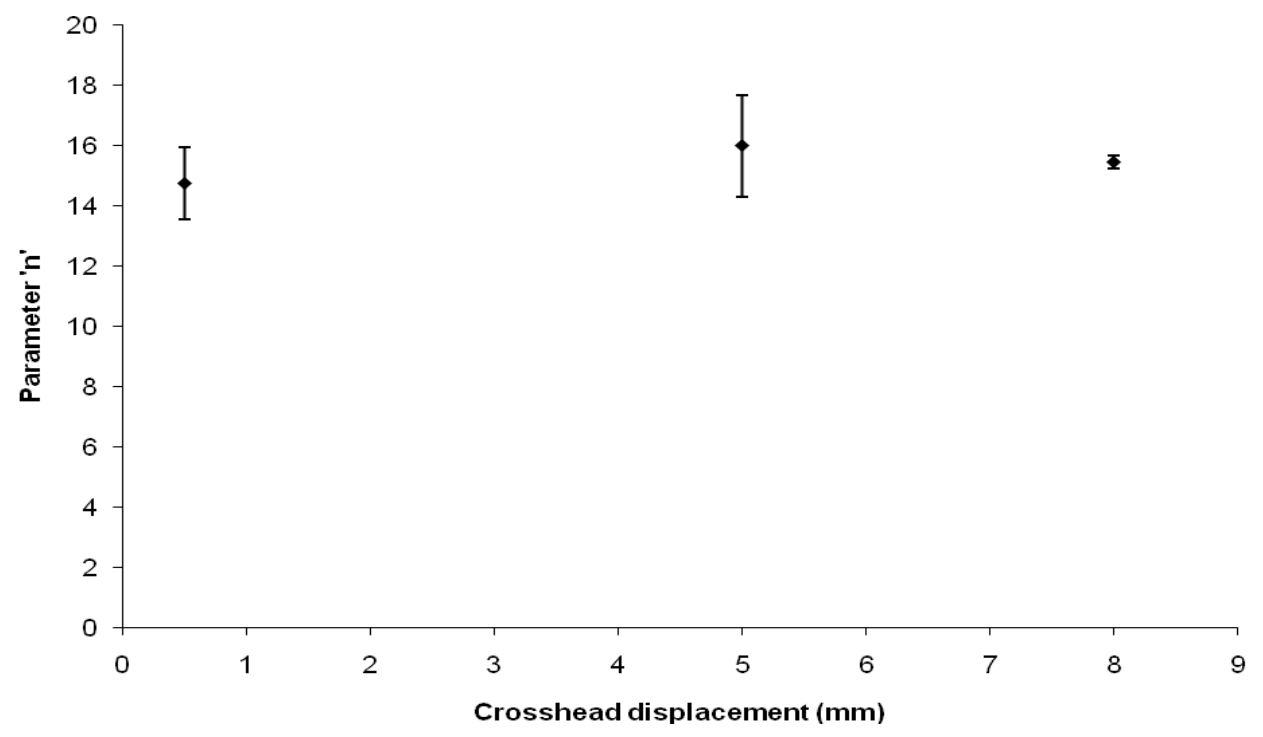

Fig. 19: Contact parameter 'n' vs crosshead displacement rate for flax fibre biocomposite.

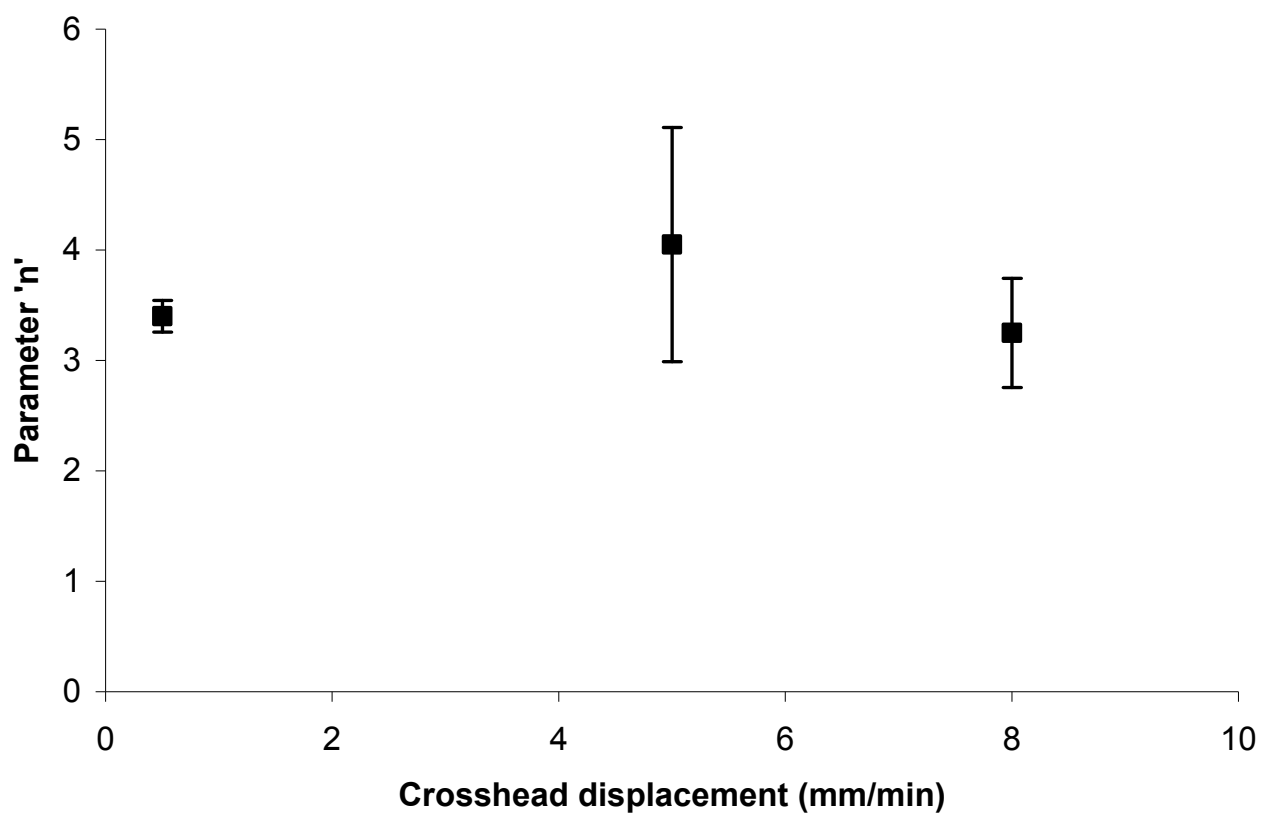

Fig. 20: Contact parameter 'n' vs crosshead displacement rate for sisal fibre biocomposite. 


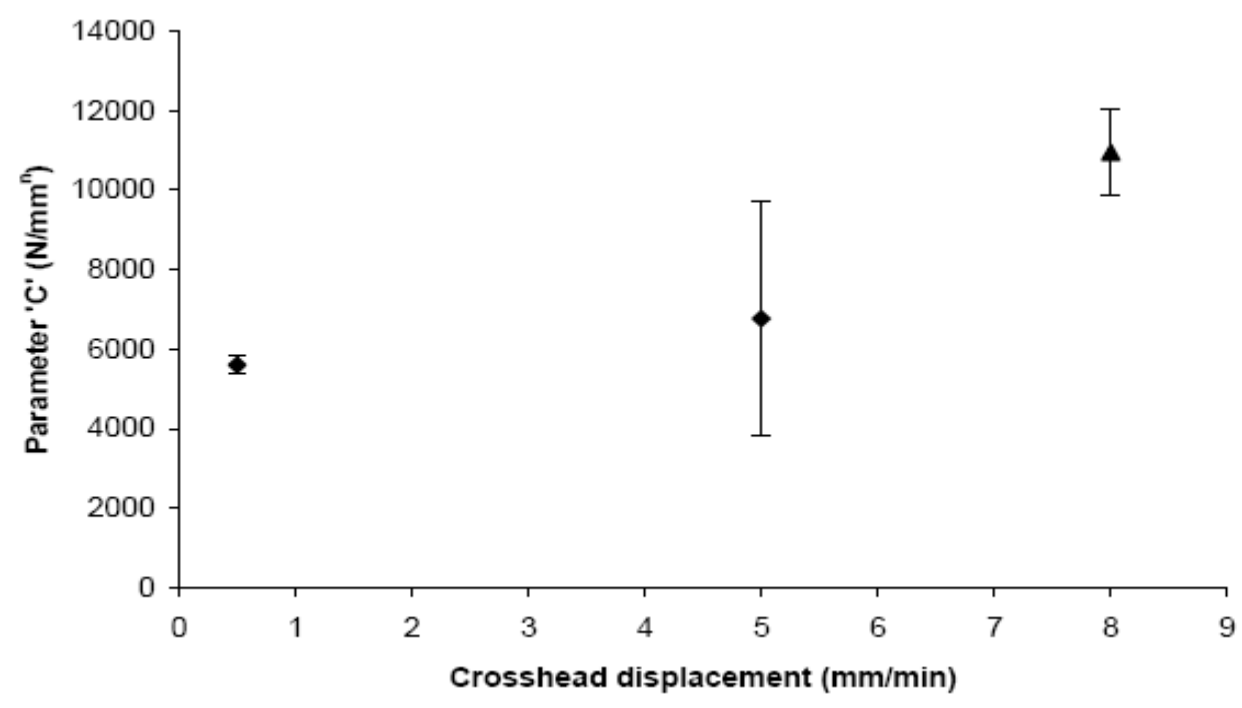

Fig. 21: Contact parameter ' $C$ ' vs crosshead displacement rate for sisal fibre biocomposite.

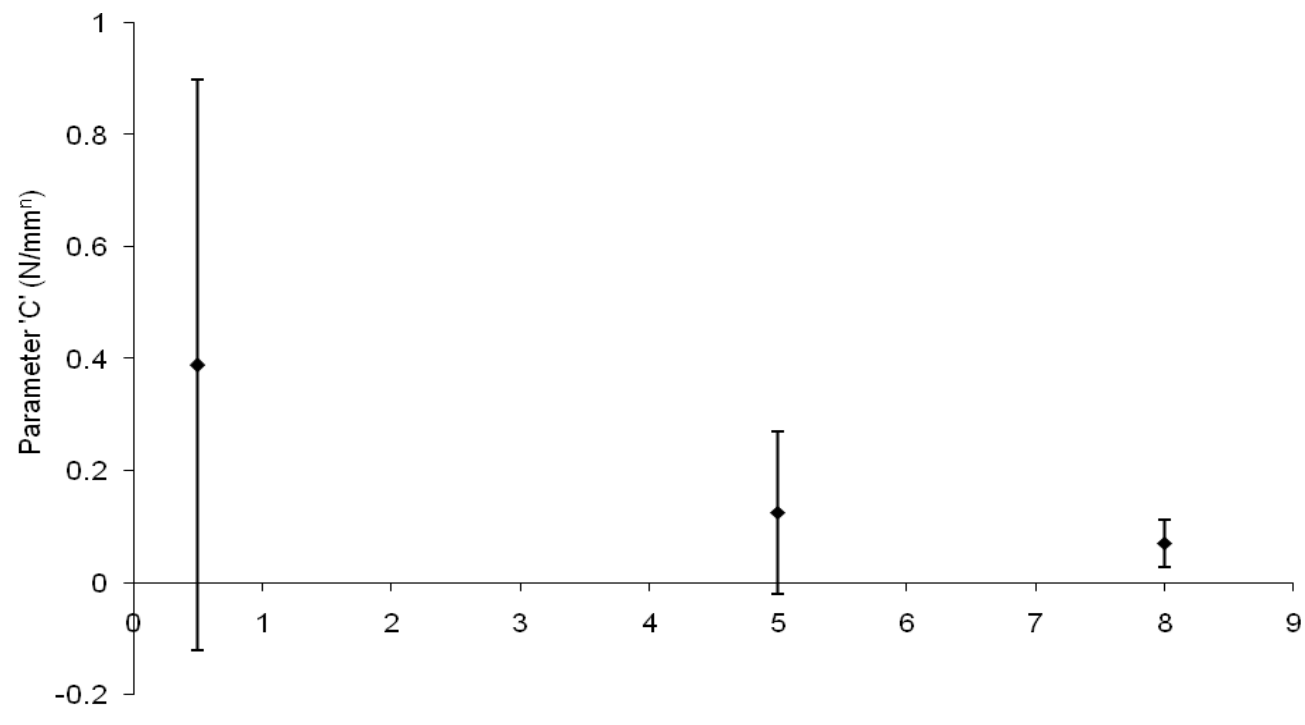

Crosshead displacement $(\mathrm{mm} / \mathrm{min})$

Fig. 22: Contact parameter ' $C$ ' vs crosshead displacement rate for flax fibre biocomposite.

The $\mathbf{n}$ parameter does not appear to vary much at these low rates of loading, with average values of 3.6 and 15.4 for the sisal fibre reinforced composite and flax fibre reinforced composite respectively (Figs 19 and 20). These results are above the 1.5 value obtained for Hertz contact between two elastic bodies. In Figs 21 and 22 the relationship between the contact parameter $\boldsymbol{C}$ and the crosshead speed of the indenter is plotted. This quantity is rate dependent and the mean value increases with the crosshead displacement rate but not in a proportional manner for the sisal fibre composites, while the reverse is the case for the flax fibre composites. The conclusion for the quantity $\boldsymbol{n}$ may be relevant at low rate of loading on the quasi-unidirectional natural fibre reinforced composites because it not sensitive to the strain rates and hence may be useful in modelling on such systems. 


\section{Concluding remarks}

Bio-composites are gradually emerging as a viable alternative to synthetic fibre reinforced composites in some industrial applications. In this study, quasiunidirectional, aligned natural fibre/polyester composites containing about $40 \%$ volume fraction of the fibre were subjected to dynamic loads at various sample temperatures and static indentation test at various crosshead speeds. The initial rise in the load history plots is almost smooth and identical, indicating an elastic response up to the point of load drop. The stick - slip drop in load implies progressive local failure of the composite, especially after the peak. They exhibit favourable non-brittle fracture on impact; a good requirement in certain applications such as crashworthiness. The following conclusions may be drawn from the results of this study.

- Within the limits of the error bars both natural fibre composites incur almost the same damage as shown by the impact properties.

- As time is required to generate damage the higher contact time of the composites reinforced with flax as quasi-unidirectional, was less tolerant to damage.

- The crack paths through the composites were irregular.

- Natural fibre composites show better shatter resistant and energy dissipation characteristics compared to the synthetic fibre reinforced composite.

- Composites tested at $9 \mathrm{~J}$ and $12 \mathrm{~J}$ impact resulted in cracking of the matrix, splintering of the fibres and ultimately perforation.

- Average indentation power coefficients of 3.6 and 15.4 were realized for sisal and flax composites respectively and may be useful for the purpose of modelling.

Further studies in this investigation will involve the characteristics of some other natural fibres such as coconut and banana fibres. Also to be considered are composites reinforced with chopped natural fibres with the objective to attain quasi isotropic properties.

\section{References}

1. Wambua, P. et al'Natural fibres: can they replace glass in fibre reinforced plastics?' Composites Science and Technology 63 (2003) 1259 - 1264.

2. Schoeppner, G. A. and Abrate, S. (2000): "Delamination threshold loads for low velocity impact on composite laminates," Composites: Part A, Vol. 31, pp. 903915.

3. David-West, O S, Nash, D H and Banks, W M 'The Study of Reversible and Irreversible Impact Loading on Symmetrical and Unsymmetrical CFRP Composite Laminates'. In: International Conference on Computational and Experimental Engineering and Science, 26 - 29 July 2004, Madeira, Portugal, pp. $363-371$.

4. Abrate, S 'Impact on composite structures' Cambridge University Press: 1998.

5. Abrate S 'Impact of composite laminates' Appl Mech Rev 1991, 44(4) pp 155 190.

6. Hosur, M V, Jain, K and Jeelani, S, (2005) 'Low velocity impact response of carbon/epoxy laminates subjected to temperature and moisture conditioning' 
Proceedings of the fifteenth International Offshore and Polar Engineering Conference, Seoul, Korea, June 19 - 24, 2005, pp 503 - 508.

7. Gomez-del Rio, T, Zaera, R, Barbero, E, and Navarro, C, (2005) 'Damage in CFRPs due to low velocity impact at low temperature' Composites: Part B Vol. 36, pp $41-50$.

8. Mahesh V Hosur, Farhan Chowdhury and Shaik Jeelani (2007), 'Low-velocity Impact Response and Ultrasonic NDE of Woven Carbon/Epoxy-Nanoclay Nanocomposites' Vol. 41 (18) pp 2195 - 2212.

9. Paul Wambua, Bart Vangrimde Stepan Lomov and Ignaas Verpoest, 'The Response of natural fibre composites to ballistic impact by fragment simulating projectiles' Composite Structures 77 (2007) $232-240$.

10. Md Akil Hazizan and W J Cantwell, 'The low velocity impact response of an aluminium honeycomb sandwich structure', Composites: Part B 34 (2003) 679 687.

11. Dashin Liu, Basavaraju B. Raju and Xinglai Dang, "Impact perforation resistance of laminated and assembled composite plates", Int. J. of Impact Eng-ng 24 (2000) 733-746.

12. Gama BA, Waliul Islam SM, Rahman M, Gillespie JW, Bogetti TA, Cheeseman BA, Chian-Fong Yen and Hoppel CPR. Punch Shear Behaviour of Thick-Section Composites Under Quasi-Static Low Velocity and Ballistic Impact Loading, Sampe Journal, Vol. 41, No. 4, pp. 6-13, July/August 2005.

\section{ACKNOWLEDGEMENT}

Thanks to the EPSRC (project number EP/C509994/1) for funding this study 